\title{
FINAL FAREWELL EDITORIAL-12 YEARS OF PROGRESS
}

\author{
Stacieann C. Yuhasz, PhD
}

$\int$ n 12 years, the Journal of Rehabilitation Research and Development (JRRD) has transformed from a small Department of Veterans Affairs (VA) house-organ into a leading international rehabilitation research publication, benefitting Veterans, all persons with disabilities, and those who care for them. At JRRD, we have fully honored U.S. Public Law 729 passed in 1948, which established the original tenets for the journal's existence. It authorized a program of VA research in the fields of prosthetics and sensory devices with a mandate "to make available the results of such research so as to benefit all disabled people." This central tenet is reflected in the JRRD mission statement developed 12 years ago: "To responsibly evaluate and disseminate scientific research findings impacting the rehabilitative healthcare community."

During the past 12 years, JRRD has garnered stakeholders in over 200 countries, seen consistently increasing journal metrics and submissions (more than doubling in 12 years), realized JRRD content downloads approaching 11 million, and published cutting-edge rehabilitation content. This includes 30 highly cited single-topic issues and reflects both current trending topics such as traumatic brain injury, posttraumatic stress disorder, amputation, and prosthetics and longstanding rehabilitation areas such as stroke, chronic disease management, pain, sensory issues, assistive technology, engineering, and product evaluation, as well as more than $\mathbf{2 5}$ other topic areas. This vast multitude of rehabilitation topics reflects the concerns of Veterans in the United States, composed of persons over the age of 18 , of both sexes, and of all races and creeds, which mirrors the demographics of stakeholders within the global community. Thus, it is no surprise that the global community of rehabilitation researchers, by providing their best work to JRRD, also provides their best hope for assisting those among us who need their insights, clinical trial results, and clinical practice guidelines to further rehabilitation treatments and assistive technologies.

This progress in the past 12 years of publication has all been possible by the concerted hard work of many people:

1. The global researchers who have come to trust JRRD as their publication venue, not only for our comprehensive and accurate technical editing and transparent peer-review process, but also for our fully accessible Web content (free open-access) and complete availability from Google, PubMed, the Directory of Open Access Journals, and all other search modalities.

2. The JRRD Editorial Board, who have worked, many for my full tenure and beyond, to ensure that the JRRD peerreview process provides free and fair evaluation of every submission and that authors are given the chance to refine their submissions to meet the stringent JRRD expectations.

\section{The JRRD team.}

I save my final words of thanks for my team. These people are extremely dedicated U.S. Government employees who have consistently worked above and beyond all expectations because they know that they are making a difference in people's lives. They know that they are working for the proverbial greater good, and as such, have demonstrated time and time again their devotion to JRRD and the content we publish. They represent the best in what people can do when they work together and that is reflected in the high quality of all JRRD publications. In 12 years, we have never had to publish an erratum, corrigendum, or retraction due to their diligence in working with our authors and reviewers. They are proud of that record, which very few scientific, technical, or medical publications can match.

JRRD has passed a major milestone in publication, 50 years, of which I am honored to be a small part of for the past 12 . I hope that with your continued support, JRRD will have another 50 years of publishing the same superior quality of rehabilitation research and that future editorials will reflect on the significance of published 
content to assist our brethren. I am thankful for this unique opportunity to have served as the JRRD Editor and am proud of my Federal service. I will be resigning in mid-August and stepping down from my post, but I look forward to keeping up with JRRD in the future and wish the journal continued success.

\section{Stacieann C. Yuhasz, PhD}

Email: Stacie.yuhasz@jhu.edu

This article and any supplementary material should be cited as follows:
Yuhasz SC. Final farewell editorial-12 years of progress. J Rehabil Res Dev. 2014;51(6):ix-x. http://dx.doi.org/10.1682/JRRD.2014.04.0098

ResearcherID/ORCID: Stacieann C. Yuhasz, PhD: B-5428-2011

\begin{tabular}{|c|c|}
\hline $\begin{array}{l}\text { ALL SUBMISIONS SCREENED BY: } \\
\text { iThenticate }\end{array}$ & Mossef нанва \\
\hline WANT TO PRECHECK YOUR WORK? $\gg$ & $\begin{array}{l}\text { CROSSREF_ORG } \\
\text { THE GITATIOH LIHKING EACKEOHE }\end{array}$ \\
\hline
\end{tabular}

